\title{
Modeling key drivers of e-learning satisfaction among student teachers
}

\begin{abstract}
This study explored the key drivers of student teachers' e-learning satisfaction. Three hundred and eighty-seven participants completed a survey questionnaire measuring their self-reported responses to six constructs (tutor quality, perceived usefulness, perceived ease of use, course delivery, facilitating conditions, and course satisfaction). Data analysis was performed using structural equation modeling. The results of this study showed that, apart from facilitating conditions, all constructs were significant predictors of e-learning satisfaction. However, facilitating conditions was found to be a significant mediator of perceived ease of use and satisfaction. Some implications for e-learning and teacher education were discussed.
\end{abstract}

Keyword: E-learning satisfaction; Student teachers 